\title{
Peri-Implantitis - A Growing Complication of Dental Implant Prosthesis
}

\author{
Natasha Fatima, Muhammad Shahrukh Khan Sadiq, Durafshan Rehman
}

\begin{abstract}
- - - - - - - - - - - - - - - - - - - - - - ABSTRACT

Contemporarily, dental implant is considered as the gold standard for managing complete or partially edentulous patients. Even though with meagre rates of failure, peri-implantitis is one complication that is worth deciphering. The prevalence of peri-implantitis is reportedly increasing with time so correct diagnosis is the most important factor for proper management of peri-implant disease. Regular evaluation and elimination of risk factors (history of periodontitis, poor oral hygiene, diabetes, smoking, alcohol consumption, genetic traits, absence of keratinized mucosa and implant surface) are effective precautions against peri implantitis. The management of peri-implant mucositis is also considered as an important preventive measure for the onset of peri- implantitis. In addition to aspects of osseointegration, type and structure of the implant surface are of importance. For the treatment of peri-implant disease multiple conservative and surgical methods are available. To minimize its detrimental effects, it is important to take a holistic view of the condition. Therefore, this review gives an overview on the prevalence, etiology, risk factors, prevention and treatment of peri-implantitis.
\end{abstract}

Keywords: Complication, Dental Implant, Inflammation

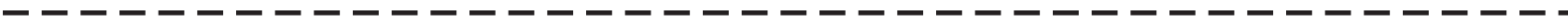

\section{INTRODUCTION:}

Dental implants have become a well-accepted therapy for the replacement of missing teeth in dentistry. Dental implants have relatively better survival rate ( $>10$ years) as compared to other dental prosthesis. ${ }^{1}$ Success rates of around $88 \%$ were reported after 15 years follow-up. ${ }^{2}$ In the last decade, increasing number of evidence have been reported on the presence of peri-implant inflammations which is one of the most common complications that effects the soft and hard tissues surrounding an implant which can eventually cause the implant loss. Therefore, strategies for treatment and prevention of peri-implant disease should be included in the modern concept of rehabilitation in dentistry.

In a successful implant, there's a tight seal between periimplant mucosa and trans-mucosal component of implant. ${ }^{3}$ It is generally considered that during initial healing phase after implant installation, there is a loss of crestal bone of around 0.5 and $2 \mathrm{~mm} .{ }^{4}$ Any additional bone loss after initial healing phase suggests peri-implant disease. ${ }^{5}$ According to a study conducted by Renvert et al; any bone loss greater than $2 \mathrm{~mm}$ is indicative of peri-implantitis. ${ }^{5}$ Clinically, periimplantitis can be determined by peri-implant mucosal inflammation, which includes redness, bleeding on probing

Natasha Fatima
Registrar, Periodontology
Bahria University Medical and Dental College, Karachi
Email: natashafatima93@yahoo.com
Muhammad Shahrukh Khan Sadiq
Lecturer, Oral Pathology
Bahria University Medical and Dental College, Karachi
Durafshan Rehman
Rahistrar, Prosthodontics
Received: 25-04-2019

and exudation, along with a loss of the supporting tissues which shows increases in probing depths and progressive radiographic bone loss. ${ }^{6}$ Multiple factors are involved in the evaluation of peri-implant health and disease which include bleeding on probing (BOP) and changes in crestal bone level with or without deepening of peri-implant pockets (PPD). ${ }^{7}$

\section{METHODOLOGY:}

To obtain available data of interest GOOGLE and GOOGLE SCHOLAR were used as electronic databases. The literature search was performed on articles published from 2014 to 2018. Key words such as Peri-implantitis, periimplant mucositis, definition of periimplantitis, risk factors, and treatment of perimplantitis were used. Among 200 articles, 44 were short listed on the basis of suggested title. A major content of this article was based on risk factors and treatment options available for periimplantitis. Figure-1.

\section{LITERATURE REVIEW:}

DEFINITION AND DIAGNOSIS: In comparison with gingivitis and periodontitis which is affecting natural teeth, disease affecting soft and hard tissue surrounding implant is called peri-implant mucositis and peri-implantitis. Periimplant mucositis is an inflammation of the soft tissues or

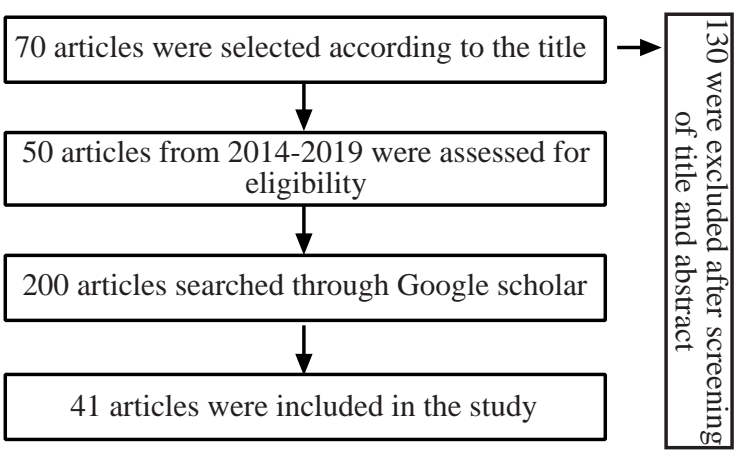


mucosa surrounding a dental implant, without additional bone loss after the initial bone remodeling that may occur during healing following the surgical placement of the implant. ${ }^{8}$ Whereas 'Peri- implantitis is an inflammatory lesion of the mucosa surrounding an endosseous implant and with progressive loss of supporting peri-implant bone'. ${ }^{3}$ It is thought that peri-implant mucositis usually leads to peri-implantitis if not treated on time.

\section{ETIOLOGY AND PREVALENCE:}

There are several reports on the prevalence of peri-implantitis which range from 1 to $47 \%$. In a systematic review, the weighted mean prevalence of peri-implantitis was $22 \%$. ${ }^{9}$ Prevalence of peri-implantitis was evaluated, and revealed that $10 \%$ of all inserted implants and $20 \%$ of all implanted patients showed peri-implantitis. ${ }^{13}$ Peri-implantitis results from an imbalance between the host response and oral biofilm at the implant surfaces. Formation of a bacterial biofilm around the implant is considered as a main etiological factor in the development of peri-implantitis. ${ }^{10} \mathrm{Gram}$ negative anaerobic bacteria found in bacterial biofilm includes Fusobacteria, Spirochetes, and black-pigmenting organisms such as Prevotella Intermedia. ${ }^{11}$

\section{RISK FACTORS:}

Correct diagnosis is the most important factor for proper management of peri-implant disease. ${ }^{14}$ The risk factors which result in peri-implantitis include history of periodontitis, poor oral hygiene, diabetes, smoking, alcohol consumption, genetic traits, absence of keratinized mucosa and implant surface. ${ }^{15}$

Oral hygiene: Microbial colonization of the implant surface takes place as soon as it is exposed to the oral cavity. ${ }^{16}$ Inaccessibility can interfere with oral hygiene maintenance which can cause peri-implantitis. ${ }^{17}$ In a study, peri-implantitis was developed in $48 \%$ of the implants due to lack of proper oral hygiene maintenance because of inaccessibility. ${ }^{18}$

History of periodontitis: Periodontitis is one of the most common oral disease which is ranked as $6^{\text {th }}$ most prevalent disorder in its severe form. ${ }^{19}$ The worldwide prevalence of periodontal disease in the general adult population is 30$35 \% .{ }^{5}$ According to WHO estimates, the prevalence of chronic periodontitis estimates in the Pakistani population is $30 \% .{ }^{20}$ Whereas in a cross sectional study, the incidence of peri-implantitis was found to be $15.1 \%$ in the nonperiodontitis and $26 \%$ in subjects with a history of periodontitis. ${ }^{21}$ Roccuzzo et al. followed 149 patients and categorized them as periodontically healthy, moderately and severely compromised. He reported that the frequency of bone loss $=3 \mathrm{~mm}(0 \%, 9.4 \%, 10.8 \%)$ and $\mathrm{PD}=6 \mathrm{~mm}(4 \%$, $16 \%, 24 \%$, respectively) was increasing significantly with each group. The result also concluded that the peri-implantitis treatment was more extensive in patients with the history of periodontitis. ${ }^{22}$ Donati et al. reported in a 20 year follow up study that the risk of peri-implantitis was more in the patients with the history of periodontitis. ${ }^{23}$ So there is strong evidence that the history of periodontitis is a major risk factor in the development of peri-implantitis with different outcome of implant therapy in patients with or without periodontal disease.

Diabetes mellitus is a chronic metabolic disease which presented as hyperglycemia with other side effects. Diabetes as a relative contraindication for implant has always been controversial due to impaired healing found in diabetic patients. ${ }^{24}$ Aguilar-Salvatierra reported that the peri-implantitis increased with patients having elevated level of HbA1c. ${ }^{25}$ The cross-sectional study of 5 years conducted by Daubert Dm et al. showed an elevated risk for peri-implantitis of 1.9 in diabetics. ${ }^{26}$ On contrary, the prospective study of Oates et al. reported no evidence of clinical signs of peri-implantitis 1 year after implantation. ${ }^{27}$

Smoking: Smoking causes impairment of various adaptive and innate host responses. ${ }^{28}$ Several studies have affiliated smoking with dry socket, tooth loss, periodontitis and impaired wound healing post-surgery. ${ }^{29}$ Another study evaluated that the smoking has a negative effect on implant survival. ${ }^{30}$ The patients who smoke before the placement of implant were $35 \%$ more prone to implant failure and those who smoke after placement have $75 \%$ risk of failure as compared to non-smokers. ${ }^{(31,32)}$ The relationship between peri-implantitis with smoking is still controversial, as some studies have failed to identify any significant differences of peri-implantitis among smokers and non-smokers. ${ }^{(33,34.35)}$ Thus, the information available on the smoking as a risk factor to peri-implantitis is still insufficient.

Implant surface: In vivo studies showed no correlation between design and surface texture of the trans-mucosal portion of implants to peri-implantitis. The development of peri-implantitis is not effected by dimensions of keratinized tissues present between mucogingival junction and the periimplant mucosal margin. Some evidence studies suggest that excess cement is also a risk factor for peri-implant imflammation. $^{12}$

\section{TREATMENT:}

Surgical treatment is usually required to treat peri-implantitis whereas only nonsurgical therapy can be used to treat to peri-implant mucositis. It was particularly emphasized proper oral hygiene maintenance, diagnosis and professional plaque removal is required to prevent any implant related disease. ${ }^{12}$ Adjunctive therapy (use of antiseptic mouthwashes/ antibiotics) showed no improvement in the efficacy of professionally administered plaque removal (PAPR) in peri implant disease patients. ${ }^{36}$

Non-Surgical Treatment: Peri-implantitis is not completely eliminated by mechanical debridement alone. Therefore, adjunctive therapies rather than mechanical debridement alone have been recommended, such as laser, antibiotics, and photodynamic therapy. ${ }^{37}$ A randomized clinical trial 
about peri-implant therapy showed that non-surgical mechanical therapy alone and with adjunctive use of Perisolv(chloramine based oral gel), are equally effective in treatment of peri-implantitis up to 3 months. ${ }^{38}$ Another study showed Adjunctive therapy (use of antiseptic mouthwashes/antibiotics) showed no improvement in the efficacy of professionally administered plaque removal (PAPR) in peri implant disease patients. ${ }^{36}$ Another study of peri-implant mucositis do not recommended adjunctive antiseptics/antibiotics (local and systemic) over alone. A study by Schwarz et al. recommended alternative measures for plaque removal (i.e. Glycine powder air polishing, erbium- doped, yttrium aluminium garnet laser-ERL) and adjunctive local antibiotics over the MD alone ${ }^{39} \mathrm{~J}$ Gordon et al, assessed the long-term clinical outcomes following non-surgical therapy of peri-implant diseases and concluded that both mechanical debridement with Chlorhexidine and ERL were successful on the long-term, but failed to attain a complete disease resolution. ${ }^{40}$

Surgical treatment: De Waal et al. suggest that "experience of the surgical team," "amount of bone loss" and "smoking" are the factors which indicate the prognosis of surgical treatment of peri-implantitis. ${ }^{41}$ It is reported that at least 12 months follow up is required to evaluate the effects of surgical treatment but 6 months follow up can also be useful as patient enters maintenance phase by 6 months. ${ }^{42}$

Resective peri-implantitis surgery: Koldsland et al. conducted a study on short-term effects of surgical treatment of periimplantitis, and its prognostic indicators. He indicated that the inflammation is reduced by resective peri-implantitis surgery but bleeding on probing/suppuration was still present which requires evaluation and long-term maintenance. The presence of suppuration and bone loss of more than $7 \mathrm{~mm}$ prior to surgical treatment reduces the effects of treatment. ${ }^{43}$

Smoking has a negative prognostic effect on the surgical treatment of peri-implantitis. ${ }^{41}$ Characteristics of implant surface also have an impact on the prognosis of surgical treatment of peri-implantitis. ${ }^{44}$ Machined/smooth surfaces recorded to have less inflammation than the modified implant surface. However this variable was not recognized as a prognostic indicator in multilevel studies. ${ }^{43}$ The location of implant also plays a part in outcome of the treatment. Lingual and buccal sites have less pocket depth and bop as compared to approximal sites. There are several possible reasons for this. First, buccal/lingual sites shows more mucosal recession. Secondly, alveolar bone of neighboring teeth have a higher level which might create a bony inclination towards the implant. In addition, the location of the implant site is also effected by accessibility of oral hygiene. ${ }^{43}$

\section{CONCLUSION:}

Peri-implantitis is a severe complication that results in failure of dental implants. Thus, proper oral hygiene along with concerned local and systemic factors should be kept in view to prevent the inflammation of the surrounding tissues of the implant. Various surgical and non-surgical treatment modalities are also available to counter peri-implantitis and should be applied as per their indications. Correct diagnosis of peri-implant disease is critical for appropriate management of peri-implant disease.

\section{REFERENCES:}

1. Derks J, Schaller D, Håkansson J, Wennström JL, Tomasi C, Berglundh T. Effectiveness of implant therapy analyzed in a Swedish population: prevalence of peri-implantitis. Journal of dental research. 2016;95(1):43-9.

2. Kandasamy B, Kaur N, Tomar GK, Bharadwaj A, Manual L, Chauhan M. Long-term Retrospective Study based on Implant Success Rate in Patients with Risk Factor: 15-year Followup. The journal of contemporary dental practice. 2018;19(1):903.

3. Renvert S, Persson GR, Pirih FQ, Camargo PM. Peri-implant health, peri-implant mucositis, and peri-implantitis: Case definitions and diagnostic considerations. Journal of clinical periodontology. 2018;45:S278-85.

4. Cecchinato D, Parpaiola A, Lindhe J. Mucosal inflammation and incidence of crestal bone loss among implant patients: a 10-year study. Clinical oral implants research. 2014;25(7):7916.

5. Renvert S, Aghazadeh A, Hallström H, Persson GR. Factors related to peri-implantitis-a retrospective study. Clinical oral implants research. 2014;25(4):522-9.

6. Ramanauskaite A, Becker K, Schwarz F. Clinical characteristics of peri-implant mucositis and peri-implantitis. Clinical oral implants research. 2018;29(6):551-6.

7. Coli P, Christiaens V, Sennerby L, Bruyn HD. Reliability of periodontal diagnostic tools for monitoring peri-implant health and disease. Periodontology 2000. 2017;73(1):203-17.

8. Poli PP, Cicciu M, Beretta M, Maiorana C. Peri-implant mucositis and peri-implantitis: A Current understanding of their diagnosis, clinical implications, and a report of treatment using a combined therapy approach. Journal of Oral Implantology. 2017;43(1):45-50.

9. Derks J, Tomasi C. Peri-implant health and disease. A systematic review of current epidemiology. Journal of clinical periodontology. 2015;42:S158-71.

10. Heitz-Mayfield LJ, Salvi GE. Peri-implant mucositis. Journal of clinical periodontology. 2018;45:S237-45.

11. Kýran B, Toman M, Buduneli N, Lappin DF, Toksavul S, Nizam N. Intraoral versus extraoral cementation of implantsupported single crowns: Clinical, biomarker, and microbiological comparisons. Clinical implant dentistry and related research. 2018;20(2):170-9.

12. Jepsen S, Berglundh T, Genco R, Aass AM, Demirel K, Derks J, Figuero E, Giovannoli JL, Goldstein M, Lambert F, OrtizVigon A. Primary prevention of peri-implantitis: Managing peri-implant mucositis. Journal of clinical periodontology. 2015;42:S152-7.

13. Smeets R, Henningsen A, Jung O, Heiland M, Hammächer C, Stein JM. Definition, etiology, prevention and treatment of peri-implantitis-a review. Head \& face medicine. 2014;10(1):34.

14. Genco, R. J. Current view of risk factors for periodontal diseases. Journal of Periodontology 1996;67:1041-1049. 
15. Dalago HR, Schuldt Filho G, Rodrigues MA, Renvert S, Bianchini MA. Risk indicators for peri-implantitis. A crosssectional study with 916 implants. Clinical oral implants research. 2017;28(2):144-50.

16. Persson GR, Renvert S. Cluster of bacteria associated with peri-implantitis. Clinical implant dentistry and related research. 2014;16(6):783-93.

17. Renvert S, Polyzois I. Treatment of pathologic peri-implant pockets. Periodontology 2000. 2018;76(1):180-90.

18. Renvert S, Quirynen M. Risk indicators for peri-implantitis. A narrative review. Clinical oral implants research. 2015;26:1544.

19. Kassebaum NJ, Bernabé E, Dahiya M, Bhandari B, Murray CJ, Marcenes W. Global burden of severe periodontitis in 1990-2010: a systematic review and meta-regression. Journal of dental research. 2014;93(11):1045-53.

20. Khan S, Khalid T, Awan KH. Chronic periodontitis and smoking Prevalence and dose-response relationship. Saudi medical journal. 2016;37(8):889.

21. Rokn A, Aslroosta H, Akbari S, Najafi H, Zayeri F, Hashemi $\mathrm{K}$. Prevalence of peri-implantitis in patients not participating in well-designed supportive periodontal treatments: a crosssectional study. Clinical oral implants research. 2017;28(3):3149.

22. Roccuzzo M, Bonino L, Dalmasso P, Aglietta M. Long-term results of a three arms prospective cohort study on implants in periodontally compromised patients: 10 -year data around sandblasted and acid-etched (SLA) surface. Clinical Oral Implants Research. 2014;25(10):1105-12.

23. Donati M, Ekestubbe A, Lindhe J, Wennström JL. Marginal bone loss at implants with different surface characteristicsA 20-year follow-up of a randomized controlled clinical trial. Clinical oral implants research. 2018;29(5):480-7.

24. Naujokat H, Kunzendorf B, Wiltfang J. Dental implants and diabetes mellitus-a systematic review. International journal of implant dentistry. 2016;2(1):5.

25. Gómez-Moreno G, Aguilar-Salvatierra A, Rubio Roldán J, Guardia J, Gargallo J, Calvo-Guirado JL. Peri-implant evaluation in type 2 diabetes mellitus patients: a 3 -year study. Clinical oral implants research. 2015;26(9):1031-5.

26. Daubert DM, Weinstein BF, Bordin S, Leroux BG, Flemmig TF. Prevalence and predictive factors for peri-implant disease and implant failure: a cross-sectional analysis. Journal of periodontology. 2015;86(3):337-47.

27. Oates Jr TW, Galloway P, Alexander P, Green AV, Huynh-Ba G, Feine J, McMahan CA. The effects of elevated hemoglobin Alc in patients with type 2 diabetes mellitus on dental implants. The Journal of the American Dental Association. 2014;145(12):1218-26.

28. White PC, Hirschfeld J, Milward MR, Cooper PR, Wright HJ, Matthews JB, Chapple IL. Cigarette smoke modifies neutrophil chemotaxis, neutrophil extracellular trap formation and inflammatory response-related gene expression. Journal of periodontal research. 2018;53(4):525-35.

29. Csikar J, Kang J, Wyborn C, Dyer TA, Marshman Z, Godson J. The self-reported oral health status and dental attendance of smokers and non-smokers in England. PLoS One. 2016;11(2):e0148700.

30. Gürlek Ö, Gümü ${ }^{\circ}$ P, Buduneli N. Smokers have a higher risk of inflammatory peri-implant disease than non-smokers. Oral diseases. 2018;24(1-2):30-2.
31. Sgolastra F, Petrucci A, Severino M, Gatto R, Monaco A. Smoking and the risk of peri-implantitis. A systematic review and meta-analysis. Clinical oral implants research. 2015; 26(4):e62-7.

32. Sun C, Zhao J, Jianghao C, Hong T. Effect of heavy smoking on dental implants placed in male patients posterior mandibles: a prospective clinical study. Journal of Oral Implantology. 2016;42(6):477-83.

33. Aguirre-Zorzano LA, Estefanía-Fresco R, Telletxea O, Bravo M. Prevalence of peri-implant inflammatory disease in patients with a history of periodontal disease who receive supportive periodontal therapy. Clinical oral implants research. 2015; 26(11):1338-44.

34. Daubert DM, Weinstein BF, Bordin S, Leroux BG, Flemmig TF. Prevalence and predictive factors for peri-implant disease and implant failure: a cross-sectional analysis. Journal of periodontology. $2015 \mathrm{Mar} ; 86(3): 337-47$.

35. Canullo L, Peñarrocha-Oltra D, Covani U, Botticelli D, Serino G, Penarrocha M. Clinical and microbiological findings in patients with peri-implantitis: a cross-sectional study. Clinical oral implants research. 2016;27(3):376-82.

36. Schwarz F, Becker K, Sager M. Efficacy of professionally administered plaque removal with or without adjunctive measures for the treatment of peri-implant mucositis. A systematic review and meta-analysis. Journal of clinical periodontology. 2015;42:S202-13.

37. Bassetti M, Schär D, Wicki B, Eick S, Ramseier CA, Arweiler NB, Sculean A, Salvi GE. Anti-infective therapy of peri implantitis with adjunctive local drug delivery or photodynamic therapy: 12-month outcomes of a randomized controlled clinical trial. Clinical oral implants research. 2014;25(3):27987.

38. Roos-Jansåker AM, Almhöjd US, Jansson H. Treatment of peri-implantitis: clinical outcome of chloramine as an adjunctive to non-surgical therapy, a randomized clinical trial. Clinical oral implants research. 2017;28(1):43-8.

39. Schwarz F, Schmucker A, Becker J. Efficacy of alternative or adjunctive measures to conventional treatment of periimplant mucositis and peri-implantitis: a systematic review and meta-analysis. International Journal of Implant Dentistry. 2015;1(1):22.

40. John G, Becker J, Schmucker A, Schwarz F. Non-surgical treatment of peri-implant mucositis and peri-implantitis at two-piece zirconium implants: A clinical follow-up observation after up to 3 years. Journal of clinical periodontology. 2017;44(7):756-61.

41. de Waal YC, Raghoebar GM, Meijer HJ, Winkel EG, van Winkelhoff AJ. Prognostic indicators for surgical periimplantitis treatment. Clinical oral implants research. 2016; 27(12):1485-91.

42. Sanz M, Chapple IL, Working Group 4 of the VIII European Workshop on Periodontology*. Clinical research on periimplant diseases: consensus report of $\mathrm{W}$ orking $\mathrm{G}$ roup 4. Journal of clinical periodontology. 2012;39:202-6.

43. Koldsland OC, Wohlfahrt JC, Aass AM. Surgical treatment of peri-implantitis: Prognostic indicators of short-term results. Journal of clinical periodontology. 2018;45(1):100-13.

44. Carcuac O, Derks J, Charalampakis G, Abrahamsson I, Wennström J, Berglundh T. Adjunctive systemic and local antimicrobial therapy in the surgical treatment of periimplantitis: a randomized controlled clinical trial. Journal of dental research. 2016;95(1):50-7. 